\title{
Changes in body fatness affect cardiovascular outcomes more than changes in physical activity
}

\author{
Suziane U. Cayres, ${ }^{1}$ Han C. G. Kemper, ${ }^{2}$ Luiz C. M. Vanderlei, ${ }^{3}$ Juliano Casonatto, ${ }^{4}$ \\ Aristides M. Machado-Rodrigues, ${ }^{5}$ Maurício F. Barbosa, ${ }^{6}$ Rômulo A. Fernandes ${ }^{7}$ \\ ${ }^{1}$ Post-Graduate Program in Movement Sciences, Sao Paulo State University (UNESP), Rio Claro, Brazil; ${ }^{2}$ Department \\ of Occupational Health, EMGO + Institute for Health and Care Research, VU University Medical Center, VU \\ University Amsterdam, Amsterdam, The Netherlands; ${ }^{3}$ Department of Physical Therapy, UNESP, Presidente Prudente; \\ ${ }^{4}$ Department of Physical Education, Northern Parana University (UNOPAR), Londrina, Brazil; ${ }^{5}$ Faculty of Sport \\ Sciences and Physical Education, University of Coimbra, Coimbra, Portugal; ${ }^{6}$ Post-Graduate Program in Radiology, \\ Federal University of São Paulo (UNIFESP), Sao Paulo; ${ }^{7}$ Laboratory of Investigation in Exercise - LIVE, Department \\ of Physical Education, UNESP, Presidente Prudente, Brazil
}

\begin{abstract}
Objective: The aim of this study was to analyse whether changes in physical activity and body fatness are related to modifications in cardiovascular risk factors among adolescents. Material and methods: A sample of 89 healthy adolescents was recruited for this study. We assessed habitual physical activity, body fat percentage, arterial thickness, blood sample, and biological maturation. Multivariate models were used to analyse the relationships between independent and dependent variables. Results: Physical activity (mean difference: 429.4 steps [95\% confidence interval $=-427$ to 1286$]$ ) and body fatness (mean difference: $-0.7 \%$ [95\% confidence interval $=-1.6-0.2]$ ) remained stable during the study period. Independent of changes in physical activity, for each percentage increase in body fatness, femoral intima-media thickness increased by $0.007 \mathrm{~mm}(\beta=0.007$ [95\% confidence interval $=$ $0.001-0.013])$. Longitudinal relationships were found for high-density lipoprotein-cholesterol $(\beta=-0.477 \mathrm{mg} / \mathrm{dl}$ [95\% confidence interval $=-0.805$ to -0.149$])$ and triacylglycerol $(\beta=2.329 \mathrm{mg} / \mathrm{dl}[95 \%$ confidence interval $=$ 0.275-4.384]). Conclusion: Changes in body fatness are more important than the amount of physical activity on cardiovascular and metabolic risks.
\end{abstract}

Keywords: Adolescent; physical activity; adiposity; atherosclerosis; dyslipidaemias

Received: 19 May 2016; Accepted: 30 September 2016; First published online: 12 December 2016

A HIGH LEVEL OF PHYSICAL ACTIVITY HAS BEEN pointed out as relevant behaviour in preventing obesity and metabolic and cardiovascular outcomes since the first decade of life; ${ }^{1,2}$ however, despite this, its prevalence in paediatric populations has decreased in recent years. ${ }^{3}$

During adolescence, physiological processes in humans are guided by biological maturation, affecting the development of organs and tissues, as well as physical

Correspondence to: S. U. Cayres, PhD Student, Department of Physical Education, Roberto Simonsen Street, 305, Presidente Prudente, São Paulo 19060900, Brazil. Tel: 183229 5400; E-mail: suziungari@yahoo.com.br growth. ${ }^{2}$ Hypertrophy and hyperplasia of adipose tissue are strongly affected by maturational events during this period of life, mainly in adolescents who are already obese, ${ }^{4}$ whereas obesity is intimately related to metabolic outcomes from early life. ${ }^{5,6}$ A wide variety of chronic diseases manifested in adulthood begin to develop in early life, and childhood obesity seems to have an important role in these pathogenic processes. ${ }^{5,6}$ Indeed, atherosclerosis is an inflammatory disease in which immune mechanisms and metabolic variables act together in the formation of atheroma. ${ }^{7}$ Early stages of atheroma have been identified in young populations, ${ }^{7}$ and thus measures of artery intima-media thickness and 
assessment of dyslipidaemia constitute surrogate markers of cardiovascular disease since early life. ${ }^{5}$

The literature is consistent in emphasising that prevention of chronic diseases in adulthood is essentially supported by actions initiated in early life, ${ }^{8,9}$ which should be focussed on promoting physical activity and preventing obesity. ${ }^{2,10,11}$ Most studies that have focussed on the interaction between obesity, physical activity, and markers of chronic diseases in adolescence are based on cross-sectional designs, whereas only a few of these studies take into account the effect of biological maturation. Moreover, physical activity and body fatness are commonly assessed using imprecise tools such as questionnaires and anthropometric variables, respectively. Therefore, the actual effects of physical activity and body fatness on cardiovascular and metabolic outcomes during adolescence remain unclear.

In the context of the preceding trends, the objectives of this study were (i) to analyse whether changes in physical activity and body fatness are related to modifications in cardiovascular risk factors among adolescents, and (ii) to identify whether these possible effects related to physical activity and body fatness are independent of each other.

\section{Materials and methods}

\section{Sample}

The sample included adolescents between 11 and 14 years of age who agreed to participate in the cohort study entitled "Effect of habitual physical activity and body fatness on the cardiovascular system of adolescents: cohort of 12 months", conducted in Presidente Prudente city, State of Sao Paulo, Brazil (200,000 inhabitants and human development index $=0.806$ ). Additional information about sampling procedures is provided elsewhere. ${ }^{12}$ In brief, seven large public and primary schools in the metropolitan region of the city were invited to participate in the study, and participants were recruited from the three schools that agreed to participate; the final decision about participation of the school was taken by the principal of the school. In the three participating schools, all adolescents between 11 and 14 years of age were invited to participate in the present study (overall students $n=495$ ). The following inclusion criteria were adopted: aged between 11 and 14 years; regularly enrolled in the school unit; absence of any known diseases; no regular medicine use; and signature of parents/legal guardians. Baseline measures were obtained from 120 adolescents, whereas follow-up measures were obtained from 89 adolescents $(25.8 \%$ dropouts) (Fig 1).

This cohort study was previously approved by the Ethics Committee for Research involving human subjects of the Sao Paulo State University (UNESP [process: 322.650/2013]) from Presidente Prudente, Brazil.

\section{Variables}

Body fatness. Whole-body fatness (\%) was estimated using a densitometry scanner (Lunar-DPX-NT, General Electrics; General Electric Healthcare, Little Chalfont, Buckinghamshire, United Kingdom). Before each day of assessment, the accuracy of the device was assessed following the recommended procedures of the manufacturer. During the test, the adolescents remained immobile for 15 minutes in the supine position, with their arms and legs extended on the stretcher. The patients removed their shoes and any metal objects before evaluation. The radiation was not dangerous to health. ${ }^{13}$ Body fatness was estimated using the software GE Medical System Lunar (version 4.7). All measurements at baseline and follow-up were taken by the same trained researcher, in a room with constant temperature. Baseline measures included 120 adolescents, whereas in data of 86 adolescents were assessed at follow-up.

Habitual physical activity. The amount of habitual physical activity was estimated through step counts (Yamax Digiwalker SW200) for seven consecutive days; the battery status of each device was previously tested by a voltmeter (Minipa ET-1002). This equipment was fixed to the clothes near the hip. The participants were instructed to remove the equipment while sleeping and during activities performed in water, such as swimming and showering. The device is sensitive to movements on the vertical axis, and in this way the number of steps is computed. Before sleeping, after removing the equipment, the adolescents were instructed to register the number of steps per day on a specific recording sheet. At both moments of the study, only adolescents with 7 consecutive days of physical activity were analysed, and thus the baseline measures were composed of 120 adolescents, whereas at followup data of 87 adolescents were assessed.

Intima-media thickness. At both time points baseline and follow-up - the carotid and femoral intima-media thickness (in $\mathrm{mm}$ ) were measured (right side) by the same medical doctor, with good experience in such measures, in a private hospital. The devise used was a Doppler ultrasound (Philips HD 11 XE; Philips, Barueri, Brazil), equipped with a high-resolution, multi-frequency linear transducer, adjusted for $12 \mathrm{MHz}$. All the recommendations of the Brazilian Society of Cardiology ${ }^{14}$ - for example, artery location, insonation angle, Doppler frequency, and gate width were adopted. For carotid artery assessment, the neck was lightly hyper-extended and inclined at an angle of $\sim 45^{\circ}$. In parallel, during femoral artery measurement, the leg was extended on the stretcher, and the 


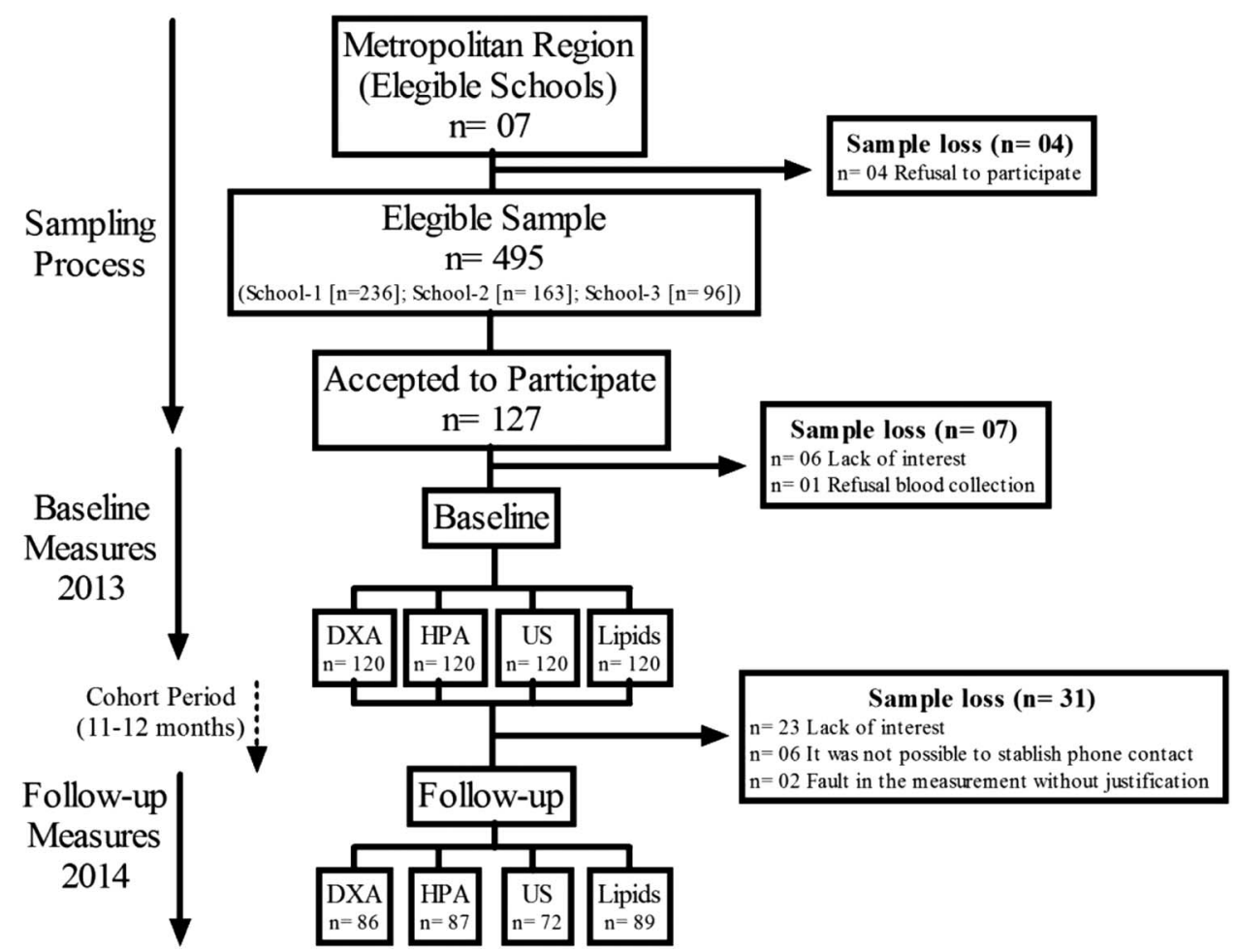

Figure 1.

Stages of the sampling procedure. DXA = bone densitometry; HPA = habitual physical activity; US = ultrasonography.

measurement was taken near the inguinal line. Reproducibility measures were provided by carotid intima-media thickness (intraclass correlation coefficient: 0.57 ; p-value $=0.029$ ) and femoral intimamedia thickness (intraclass correlation coefficient: 0.91 ; $\mathrm{p}$-value $=0.001)$ in $13.3 \%$ of the sample $(n=16$ adolescents). Baseline measures were obtained from 120 adolescents, whereas follow-up measures were obtained from 72 adolescents.

Blood pressure. Systolic and diastolic blood pressures were measured using the oscillometric method, with an automatic equipment (HEM 742 INT, Omron Healthcare Inc., Intellisense; Bannockburn, Illinois, United States of America), validated by Christofaro et $\mathrm{al}^{30}$. All measures were performed by a trained healthcare professional. The volunteers remained at rest while sitting down for 10 minutes as the midpoint of the right humerus of the arm was assessed using a sleeve of suitable size for the circumference of the arm; three measurements were obtained with an interval of 1 minute between them, and the mean of the last two measurements was considered. ${ }^{15}$ Baseline measures were obtained 1 from 20 adolescents, whereas follow-up measures were obtained from 89 adolescents.

\section{Metabolic variables}

Blood samples were collected in the morning, after 12 hours of fasting, by a trained nurse in a private laboratory that met all the quality control standards adopted by the Brazilian Health Ministry. Total cholesterol and its fractions - high-density lipoprotein-cholesterol, low-density lipoprotein-cholesterol, and triacylglycerol - were assessed using an enzymatic kit processed in an autoanalyzer (Dimension $\mathrm{RxL}$ Max, model Siemens Dade-Behring, Deerfield, Illinois, United States of America). Baseline measures were obtained from 120 adolescents, whereas followup measures were obtained from 89 adolescents. Highsensitive C-reactive protein was determined by the turbidimetric method (LabMax 240; LABEST brand, model LabMax 240 Chema Diagnostica, Monsano, Italy).

\section{General data, anthropometry, and biological maturation}

Ethnicity, sex, chronological age, and anthropometric variables were recorded during a face-to-face interview by a trained health researcher. Body mass was measured using a digital scale (Filizzola PL 150 model; Filizzola Ltda, Sao Paulo, Brazil) with a precision of $0.1 \mathrm{~kg}$. Height was estimated using a stadiometer (Sanny model; American Medical of the Brazil Ltda, Sao Paulo, Brazil) with a precision of $0.1 \mathrm{~cm}$, following previous recommendations. ${ }^{16}$ Body mass index $\left(\mathrm{kg} / \mathrm{m}^{2}\right)$ was subsequently calculated as weight $(\mathrm{kg})$ divided by height squared $(\mathrm{cm})$. Leg length and sitting height were also assessed using standardised techniques, ${ }^{16}$ and waist 
circumference was measured using a metallic tape (Sanny ${ }^{\circledR}$, American Medical of the Brazil Ltda, Sao Paulo, Brazil) in centimetres. ${ }^{17}$ All measurements were performed without shoes and with light clothing.

Biological maturation was estimated using mathematical equations to estimate age at peak height velocity, ${ }^{18}$ which is an important event during the process of biological maturation. Age at peak height velocity was expressed in time (years) (negative score [time to reach peak height velocity] and positive score [the adolescent had already reached peak height velocity]). All analysed adolescents were prepubertal (negative values) at baseline.

\section{Statistical analyses}

First, normality of the data set was assessed using the Kolmogorov-Smirnov test; in this study, the normality of change values were assessed and, when necessary, logarithm transformed. The numerical variables are presented as means, standard deviations, and 95\% confidence intervals. Changes are expressed as the crude differences between follow-up and baseline measures (follow-up values minus baseline values). The Pearson's correlation (r) and its 95\% confidence interval tested the relationships between changes in physical activity, body fatness, and metabolic and cardiovascular outcomes. Partial correlation and linear regression analysed the same relationships adjusted simultaneously by baseline physical activity, change in physical activity, sex, baseline chronological age, baseline biological maturation, and changes in biological maturation for body fatness changes, and baseline body fatness, changes in body fatness, sex, baseline chronological age, baseline biological maturation, and changes in biological maturation for physical activity changes. The statistically significant relationships in the partial correlation are presented in the linear regression (expressed as $\beta$ and its $95 \%$ confidence interval). Statistical significance (p-value) was set at a p-value $<0.05$, and all analyses were performed using BioEstat (release 5.0) statistical software.

\section{Results}

After 12 months of follow-up, 89 adolescents $(12.5 \pm 0.7$ years-old) were assessed at both pre- and post-testing time points ( 43 boys and 46 girls). The amount of physical activity (mean difference: 429.4 steps [95\% confidence interval: -427 to 1286]) and body fatness (mean difference: $-0.7 \%$ [95\% confidence interval: -1.6 to 0.2$]$ ) remained stable during the 12-month period (Table 1) and were not related to each other $(\mathrm{r}=-0.074$; $\mathrm{p}$-value $=0.502)$.

On the other hand, there were differences in systolic blood pressure (mean difference: $-2.9 \mathrm{mmHg}$ [95\% confidence interval: -5.1 to -0.7$]$ ), low-density

Table 1. Descriptive analyses of the variables in the 1-year longitudinal study (Brazil, 2013-2014).

\begin{tabular}{|c|c|c|c|}
\hline Variables & Baseline (2013) [Mean (SD)] & Follow-up (2014) [Mean (SD)] & Change $(95 \% \mathrm{CI})$ \\
\hline \multicolumn{4}{|l|}{ Independent } \\
\hline HPA (steps/days) $(n=86)$ & $9444.7(3857.4)$ & $9874.1(3732.4)$ & 429.4 steps $(-427 ; 1286)$ \\
\hline $\mathrm{BF}(\%)(\mathrm{n}=87)$ & $29.2(11.3)$ & $28.5(11.6)$ & $-0.7 \%(-1.6 ; 0.2)$ \\
\hline \multicolumn{4}{|l|}{ Cardiovascular } \\
\hline $\operatorname{CIMT}(\mathrm{mm})(\mathrm{n}=72)$ & $0.458(0.045)$ & $0.458(0.038)$ & $-0.000 \mathrm{~mm}(-0.009 ; 0.009)$ \\
\hline FIMT $(\mathrm{mm})(\mathrm{n}=72)$ & $0.385(0.068)$ & $0.368(0.067)$ & $-0.016 \mathrm{~mm}(-0.004 ; 0.038)$ \\
\hline $\mathrm{SBP}(\mathrm{mmHg})(\mathrm{n}=89)$ & $111.6(11.5)$ & $108.6(11.0)$ & $-2.9 \mathrm{mmHg}(-5.1 ;-0.7)$ \\
\hline DBP $(m m H g)(n=89)$ & $68.9(11.1)$ & $67.5(30.1)$ & $-1.4 \mathrm{mmHg}(-8.7 ; 5.9)$ \\
\hline \multicolumn{4}{|l|}{ Metabolic } \\
\hline HDL-c $(\mathrm{mg} / \mathrm{dl})(\mathrm{n}=89)$ & $49.6(10.5)$ & $48.7(9.1)$ & $-0.9 \mathrm{mg} / \mathrm{dl}(-2.4 ; 0.5)$ \\
\hline LDL-c $(\mathrm{mg} / \mathrm{dl})(\mathrm{n}=89)$ & $93.7(20.2)$ & $83.9(25.1)$ & $-9.7 \mathrm{mg} / \mathrm{dl}(-14.9 ;-4.5)$ \\
\hline $\mathrm{TG}(\mathrm{mg} / \mathrm{dl})(\mathrm{n}=89)$ & $83.0(40.8)$ & $81.2(30.6)$ & $-1.8 \mathrm{mg} / \mathrm{dl}(-11.0 ; 7.3)$ \\
\hline $\mathrm{TC}(\mathrm{mg} / \mathrm{dl})(\mathrm{n}=89)$ & $160.0(24.5)$ & $151.9(26.0)$ & $-8.9 \mathrm{mg} / \mathrm{dl}(-13.1 ;-4.7)$ \\
\hline hsCRP $(\mathrm{mg} / \mathrm{L})(\mathrm{n}=89)$ & $0.49(1.73) *$ & $0.34(0.86)^{*}$ & $0.14 \mathrm{mg} / \mathrm{L}(-0.75 ; 1.04)$ \\
\hline \multicolumn{4}{|l|}{ General } \\
\hline Age (years) $(n=89)$ & $11.6(0.7)$ & $12.6(0.7)$ & 0.9 years $(0.8 ; 1.0)$ \\
\hline Biological maturation $(n=89)$ & $-2.4(0.7)$ & $-0.9(1.2)$ & 1.4 years $(1.2 ; 1.7)$ \\
\hline Weight $(\mathrm{kg})(\mathrm{n}=89)$ & $50.3(13.1)$ & $55.4(13.8)$ & $5.0 \mathrm{~kg}(4.2 ; 5.8)$ \\
\hline Height $(\mathrm{cm})(\mathrm{n}=89)$ & $153.1(19.6)$ & $161.0(6.9)$ & $7.8 \mathrm{~cm}(3.6 ; 12.1)$ \\
\hline BMI $\left(\mathrm{kg} / \mathrm{m}^{2}\right)(\mathrm{n}=89)$ & $20.6(4.2)$ & $21.1(4.3)$ & $0.5 \mathrm{~kg} / \mathrm{m}^{2}(0.2 ; 0.7)$ \\
\hline WC $(\mathrm{cm})(\mathrm{n}=89)$ & $69.8(11.1)$ & $70.6(10.4)$ & $0.7 \mathrm{~cm}(-0.2 ; 1.7)$ \\
\hline
\end{tabular}

95\% CI = confidence interval of 95\%; $\mathrm{BF}=$ body fatness; $\mathrm{BMI}=$ body mass index; CIMT = carotid intima-media thickness; DBP = diastolic blood pressure; FIMT $=$ femoral intima-media thickness; HDL-c $=$ high-density lipoprotein-cholesterol; HPA = habitual physical activity; hsCRP = highsensitive C-reactive protein; LDL-c = low-density lipoprotein-cholesterol; SBP = systolic blood pressure; TC = total cholesterol; TG = triacylglycerol; $\mathrm{WC}=$ waist circumference

*Variable presented as median and interquartile range due non-parametric distribution 
lipoprotein-cholesterol $(-9.7 \mathrm{mg} / \mathrm{dl} \quad[95 \%$ confidence interval: -14.9 to -4.5$)$, and total cholesterol $(-8.9 \mathrm{mg} / \mathrm{dl}$ [95\% confidence interval: -13.1 to -4.7$])$. Anthropometric variables and biological maturation were also different between baseline and follow-up measures.

In the univariate analysis, changes in femoral intimamedia thickness $(\mathrm{r}=0.302$ [95\% confidence interval: $0.100-0.480]$ ), high-density lipoprotein-cholesterol $(r=-0.371$ [95\% confidence interval: -0.538 to $-0.176]), \quad$ and triacylglycerol $\quad(r=0.247 \quad[95 \%$ confidence interval: $0.041-0.433]$ ) were significantly related to body fatness changes, whereas changes in physical activity were related to changes in highdensity lipoprotein-cholesterol $\quad(r=0.227 \quad[95 \%$ confidence interval: $0.020-0.416])$ and triacylglycerol $(r=-0.211$ [95\% confidence interval: -0.402 to $-0.003]$ ) (Table 2).

In the partial correlations, after adjustments for sex, age, biological maturation, body fatness for physical activity, and physical activity for \% body fatness, the changes in femoral intima-media thickness $(r=0.277$ [95\% confidence interval: 0.029-0.493]), high-density lipoprotein-cholesterol $\quad(\mathrm{r}=-0.279$ [95\% confidence interval: -0.494 to -0.031$]$ ), and triacylglycerol $(\mathrm{r}=0.299 \quad[95 \%$ confidence interval: $0.053-0.511]$ ) still remained significantly related to body fatness changes, whereas only changes in low-density lipoprotein-cholesterol $\quad(r=0.270 \quad[95 \%$ confidence interval: $0.022-0.487]$ ) were still related to changes in physical activity (Fig $2 \mathrm{a}$ and $\mathrm{b}$ ).

In this sample, for each percentage increase in body fatness, femoral intima-media thickness increased by $0.007 \mathrm{~mm}$ (95\% confidence interval $=0.001-0.013$ ). Similar longitudinal relationships were found for high-density lipoprotein-cholesterol $(\beta=-0.477 \mathrm{mg} / \mathrm{dl}$ [95\% confidence interval $=-0.805$ to -0.149$]$ ) and triacylglycerol $\quad(\beta=2.329 \mathrm{mg} / \mathrm{dl} \quad[95 \%$ confidence interval $=0.275-4.384])($ Fig $3 \mathrm{a}, \mathrm{b}$ and $\mathrm{c})$.

\section{Discussion}

A longitudinal study carried out with adolescents where modifications in body fatness had a greater effect on vascular architecture and lipid metabolism than modifications in the amount of physical activity, even after controlling for biological maturation.

Increased body fatness is a detrimental component in the development of harmful metabolic outcomes from childhood, ${ }^{5,19}$ and body fatness is commonly, inversely related to physical activity. ${ }^{20}$ In the present study, in the non-adjusted model, both body fatness and changes in physical activity were related to modifications in high-density lipoprotein-cholesterol and triacylglycerol, but in the multivariate models changes in body fatness significantly affected the relationship between modifications in these lipid outcomes and modifications in the amount of physical activity. The effect attributed to physical activity on these lipid variables was predominantly mediated by modifications in body fatness, corroborating with the idea that maintenance of higher amounts of physical activity acts on the control of body fatness during adolescence, and hence decreases the harmful effects on metabolic variables. ${ }^{20-22}$

The mediating effect of body fatness on the relationship between amount of physical activity and modifications in high-density lipoprotein-cholesterol is particularly relevant, because of the important role of high-density lipoprotein-cholesterol in vessel structure, acting in the control of low-density lipoprotein-cholesterol concentrations, inflammation, and bioavailability of nitric oxide. ${ }^{12,23}$ Disagreeing

Table 2. Pearson's correlations between changes in body fatness (BF), physical activity (PA), and metabolic and cardiovascular variables in adolescents (Brazil, 2013-2014).

\begin{tabular}{llc}
\hline Variables (changes) & \% BF change $(\mathrm{n}=86)[\mathrm{r}(95 \% \mathrm{CI})]$ & PA change $(\mathrm{n}=87)[\mathrm{r}(95 \% \mathrm{CI})]$ \\
\hline Cardiovascular & & \\
CIMT $(\mathrm{mm})(\mathrm{n}=72)$ & $0.177(-0.032$ to 0.372$)$ & $0.102(-0.109$ to 0.304$)$ \\
FIMT $(\mathrm{mm})(\mathrm{n}=72)$ & $0.302(0.100-0.480)$ & $0.160(-0.050$ to 0.356$)$ \\
SBP $(\mathrm{mmHg})$ & $0.037(-0.173$ to 0.243$)$ & $0.045(-0.165$ to 0.251$)$ \\
DBP $(\mathrm{mmHg})$ & $0.156(-0.054$ to 0.353$)$ & $0.106(-0.105$ to 0.307$)$ \\
Metabolic & & \\
HDL-c $(\mathrm{mg} / \mathrm{dl})$ & $-0.371(-0.538$ to -0.176$)$ & $0.227(0.020-0.416)$ \\
LDL-c $(\mathrm{mg} / \mathrm{dl})$ & $-0.044(-0.250$ to 0.166$)$ & $-0.154(-0.056$ to 0.351$)$ \\
TG $(\mathrm{mg} / \mathrm{dl})$ & $0.247(0.041-0.433)$ & $0.148(-0.062$ to -0.003$)$ \\
TC $(\mathrm{mg} / \mathrm{dl})$ & $0.062(-0.148$ to 0.267$)$ & $0.346)$ \\
hsCRP $(\mathrm{mg} / \mathrm{L})$ & $0.084(-0.131$ to 0.292$)$ & -0.101 to 0.320$)$ \\
\hline
\end{tabular}

$95 \% \mathrm{CI}=$ confidence of interval of $95 \%$; CIMT $=$ carotid intima-media thickness; $\mathrm{DBP}=$ diastolic blood pressure; FIMT $=$ femoral intima-media thickness; HDL-c $=$ high-density lipoprotein-cholesterol; hsCRP $=$ high-sensitive C-reactive protein; LDL-c $=$ low-density lipoprotein-cholesterol; $r=$ coefficient of Pearson's correlation; $\mathrm{SBP}=$ systolic blood pressure; $\mathrm{TC}=$ total cholesterol; $\mathrm{TG}=$ triacylglycerol 
(a)

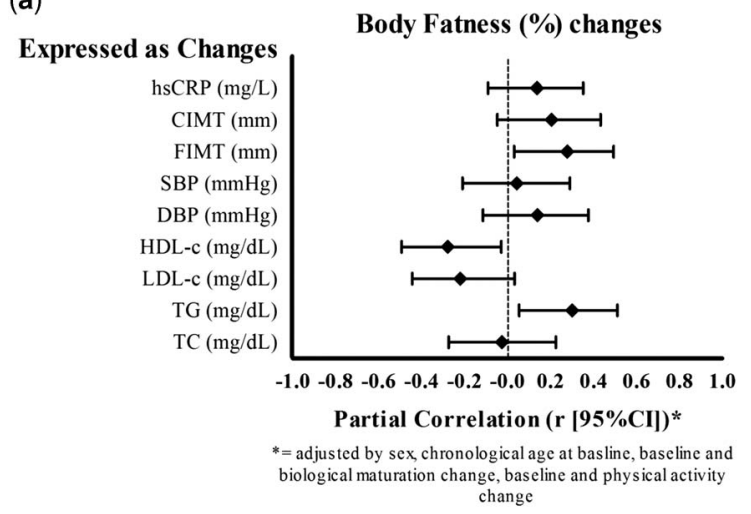

(b)

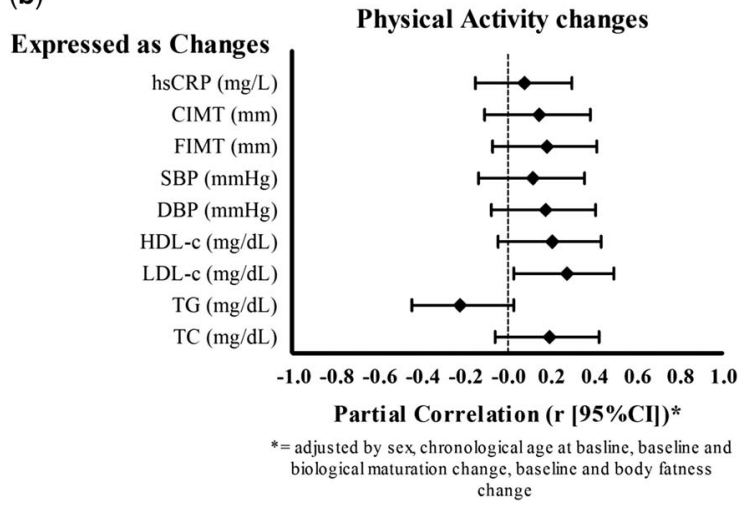

Figure 2.

Partial correlation between changes in body fatness, physical activity, and metabolic and cardiovascular variables in adolescents (Presidente Prudente, Sao Paulo, Brazil, 2014). * (a) Adjusted by sex, chronological age at baseline, baseline and biological maturation change, baseline and physical activity change. * (b) Adjusted by sex, chronological age at baseline, baseline and biological maturation change, baseline and body fatness change. 95\% CI = confidence interval of 95\%; CIMT $=$ carotid intima-media thickness; $\quad D B P=$ diastolic blood pressure; $F I M T=$ femoral intima-media thickness; $H D L-c=$ bigh-density lipoprotein-cholesterol; bs $C R P=$ bigh-sensitive $C$-reactive protein; $L D L-c=$ low-density lipoprotein-cholesterol; $S B P=$ systolic blood pressure; $T C=$ total cholesterol; $T G=$ triacylglycerol. with our findings regarding the mediating effect of adiposity, Kraus et $\mathrm{al}^{24}$ identified, after 8 months of intervention, that the amount of exercise affected both size and concentration of lipoproteins in adults, independent of modifications in weight and body mass index. Similarly, in a cross-sectional design, the amount of physical activity assessed in free-living conditions was related to lipid variables in European adolescents (both sexes and aged from 9 to 16 years-old), even after adjustment for sum of skinfolds. ${ }^{22}$ The conflicting findings could be justified by the fact that, in both studies, ${ }^{22,24}$ body fatness was assessed using less accurate methods, and therefore the effect of adiposity in the multivariate models was probably underestimated.

The present study revealed a positive relationship between arterial thickening and increases in body fatness, agreeing with previous studies; ${ }^{5}$ however, in contrast with other studies, ${ }^{25}$ carotid artery was not related to body fatness in these adolescents. This phenomenon observed in the femoral artery could be attributed, at least in part, to its calibre - smaller diameter than the carotid artery - which generates higher oscillations in blood flow and consequently higher shear stress than other vessels. ${ }^{26}$ Patterns of haemodynamic flow such as the above-mentioned ones can initiate local inflammatory processes, and thus modifications in vascular structure. ${ }^{7,12,26,27}$ The interaction between metabolic events commonly linked to obesity and the local inflammation attributed to these haemodynamic characteristics could be used to support the findings related to femoral intima-media thickness.

Some limitations should be highlighted and taken into account when considering the results of this study. The absence of measurements of physical activity intensity is a weakness. Although a pedometer provides information on the amount of physical activity, the absence of data regarding intensity is a limitation of the method, as people with similar values of step counts can present differing amounts of time engaged (a)

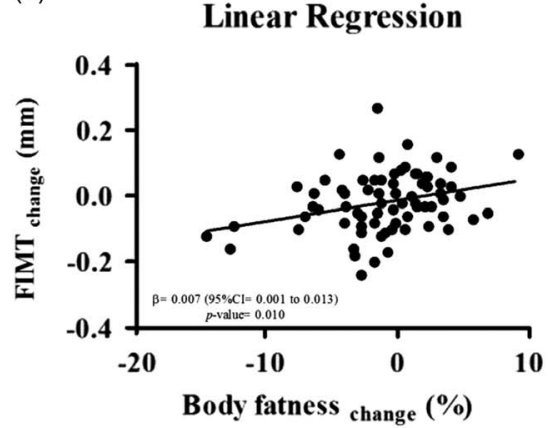

(b)

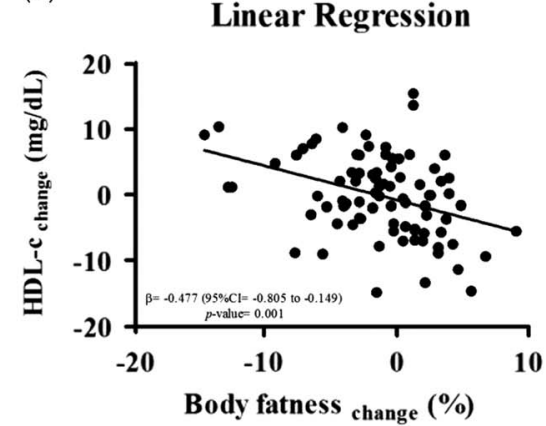

(c)

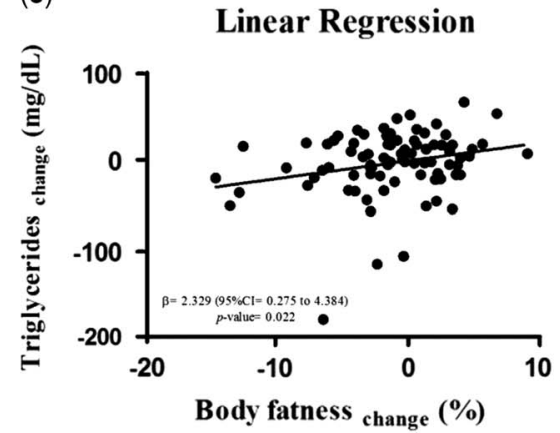

Figure 3.

Relationship between body fatness and metabolic and cardiovascular variables in adolescents (Presidente Prudente, Sao Paulo, Brazil, 2014). 95\% CI = confidence interval of 95\%; FIMT = femoral intima-media thickness; HDL-c = high-density lipoprotein-cholesterol. 
in high-intensity activities. ${ }^{28}$ The absence of a relationship between changes in physical activity and body fatness could also be explained, at least in part, by the absence of measures of intensity. In crosssectional studies involving adolescents, the amount of physical activity measured using an accelerometer was not related to body fatness, ${ }^{22}$ but the amount of physical activity performed at vigorous intensity was related and moderate intensity was not related to body fatness. Therefore, the amount of physical activity seems to be beneficial to adolescents' health only when accompanied by activities performed at high intensities, agreeing with the current paediatric guidelines. ${ }^{12,21}$ Moreover, the effect of sedentary behaviours on metabolic and cardiovascular variables should be explored in future studies, as physical activity and sedentary behaviours are important variables related to the health of young people and act in independent ways on health markers. ${ }^{29}$ The absence of markers of arterial stiffness constitutes a limitation in this study as well. Finally, the high dropout rate $(25.8 \%)$ after 12 months should be considered in future studies because of its impact on the power of the statistical analysis.

\section{Practical implications}

It is highlighted that physical activity engagement since the first decade of life is beneficial, and can positively affect adulthood. Body fatness, on the other hand, is an important mediator of cardiovascular outcomes and it seems to mediate this relationship regardless of engagement in physical activity. Taking these factors into account, futures studies should investigate the role of intensity of physical exercise on inflammation and cardiovascular outcomes in paediatric populations.

Although the importance of physical activity to promote healthy growth in paediatric populations was highlighted, this 1-year longitudinal study demonstrated that changes in adolescents' body fatness were more important than changes in the amount of physical activity on cardiovascular and metabolic risk.

\section{Acknowledgements}

The authors thank the support from Laboratory of Investigation in Exercise - LIVE, Department of Physical Education, UNESP, Presidente Prudente, Brazil, and all members involved in data collection. Authors' Contribution: C.S.U. conceptualised and designed the study, drafted the initial manuscript, and approved the final manuscript as submitted. K.H.C.G., V.L.C.M., C.J., M.-R.A.M., and B.M.F. revised the manuscript and approved the final manuscript as submitted. F.R.A. designed the data collection instruments, coordinated and supervised data collection, critically reviewed the manuscript, and approved the final manuscript as submitted. All the authors approved the final manuscript as submitted and agreed to be accountable for all aspects of the study.

\section{Financial Support}

The authors thank the State of Sao Paulo Research Support Foundation - FAPESP (Process: 2013/06052-2 [master's fellowship to SUC] and Process: 2015/04961-0 [doctorate degree to SUC]) and the Brazilian Ministry of Science and Technology, National Counsel of Technological and Scientific Development - CNPq (Process: 476295/2013-0 [research funding to RAF] and Process: 303725/2014-1 [Researcher on Productivity Level 2 to RAF]).

\section{Conflicts of Interest}

None.

\section{Ethical Standards}

The study had been previously approved by the Human Research Ethics Committee (process: 322.650/2013) and was in accordance with the National Health Council (Resolution no. 466/12).

\section{References}

1. Booth FW, Laye MJL, Lees SJ, Rector RS, Thyfault JP. Reduced physical activity and risk of chronic disease: the biology behind the consequences. Eur J Appl Physiol 2008; 102: 381-390.

2. Rubin DA, Hackney AC. Inflammatory cytokines and metabolic risk factors during growth and maturation: influence of physical activity. Med Sport Sci 2010; 55: 43-55.

3. Kemper HC, Twisk JW, van Mechelen W. Changes in aerobic fitness in boys and girls over a period of 25 years: data from the Amsterdam growth and health longitudinal study revisited and extended. Pediatr Exerc Sci 2013; 25: 524-535.

4. Knittle JL, Timmers K, Ginsberg-Fellner F, Brown RE, Katz DP. The growth of adipose tissue in children and adolescents. Cross-sectional and longitudinal studies of adipose cell number and size. J Clin Invest 1979; 63: 239-246.

5. Herouvi D, Karanasios E, Karayianni C, Karavanaki K. Cardiovascular disease in childhood: the role of obesity. Eur J Pediatr 2013; 172: 721-732.

6. Huang PL. eNOS. Metabolic syndrome and cardiovascular disease. Trends Endocrinol Metab 2009; 20: 295-302.

7. Hansson GK. Inflammation, atherosclerosis, and coronary artery disease. N Engl J Med 2005; 352: 1685-1695.

8. Lira FS, Rosa Neto JC, Antunes BM, Fernandes RA. The relationship between inflammation, dyslipidemia and physical exercise: from the epidemiological to molecular approach. Curr Diabetes Rev 2014; 10: 391-396.

9. Fernandes RA, Coelho-E-Silva MJ, Spiguel Lima MC, Cayres SU, Codogno JS, Lira FS. Possible underestimation by sports medicine of the effects of early physical exercise practice on the prevention of diseases in adulthood. Curr Diabetes Rev 2015; 11: 201-205.

10. Zago AS, Zanesco A. Nitric oxide, cardiovascular disease and physical exercise. Arq Bras Cardiol 2006; 87: e264-e270. 
11. Pahkala K, Laitinen TT, Heinonen OJ, et al. Association of fitness with vascular intima-media thickness and elasticity in adolescence. Pediatrics 2013; 132: 77-84.

12. Cayres SU, de Lira FS, Machado-Rodrigues AM, Freitas Júnior IF, Barbosa MF, Fernandes RA. The mediating role of physical inactivity on the relationship between inflammation and artery thickness in prepubertal adolescents. J Pediatr 2015; 166: 924-929.

13. Laskey MA, Crisp AJ, Cole TJ, Compston JE. Comparison of the effect of different reference data on Lunar DPX and HologicQDR-1000 dual-energy X-rayabsorptiometers. Br J Radiol 1992; 65: 1124-1129.

14. Silva CE, Tasca R, Weitzel LH, et al. Standardization of equipment and techniques for conducting echocardiographic examinations. Arq Bras Cardiol 2004; 82: 1-10.

15. Pickering TG, Hall JE, Appel LJ, et al. Recommendations for blood pressure measurement in humans and experimental animals: part 1: blood pressure measurement in humans: a statement for professionals from the Subcommittee of Professional and Public Education of the American Heart Association Council on High Blood Pressure Research. Circulation 2005; 111: 697-716.

16. Gordon CC, Chumlea WC, Roche AF. Stature, recumbent length, and weight. In: Lohman TG, Roche AF, Martorell R, (eds) Anthropometric Standardization Reference Manual. Human Kinetics Books, Champaign, IL, 1998: 3-8.

17. Katzmarzyk PT, Srinivasan SR, Chen W, et al. Body mass index, waist circumference, and clustering of cardiovascular risk factors in a biracial sample of children and adolescents. Pediatrics 2004; 114: 198-205.

18. Mirwald RL, Baxter-Jones AD, Bailey DA, Beunen GP. An assessment of maturity from anthropometric measurements. Med Sci Sports Exerc 2002; 34: 689-694.

19. da Silva DF, Bianchini JA, Antonini VD, et al. Parasympathetic cardiac activity is associated with cardiorespiratory fitness in overweight and obese adolescents. Pediatr Cardiol 2014; 35: 684-690.
20. Gutin B, Yin Z, Humphries MC, Barbeau P. Relations of moderate and vigorous physical activity to fitness and fatness in adolescents. Clin Nutr 2005; 81: 746-750.

21. Kostka T, Furgal W, Gawronski W, et al. Recommendations of the Polish Society of Sports Medicine on age criteria while qualifying children and youth for participation in various sports. Br J Sports Med 2012; 46: 159-162.

22. Ekelund U, Brage S, Froberg K, et al. TV viewing and physical activity are independently associated with metabolic risk in children: the European Youth Heart Study. PLoS Med 2006; 3: e488.

23. Yuhanna IS, Zhu Y, Cox BE, et al. High-density lipoprotein binding to scavenger receptor-BI activates endothelial nitric oxide synthase. Nat Med 2001; 7: 853-857.

24. Kraus WE, Houmard JA, Duscha BD, et al. Effects of the amount and intensity of exercise on plasma lipoproteins. N Engl J Med 2002; 347: 1483-1492.

25. Jourdan C, Wühl E, Litwin M, et al. Normative values for intimamedia thickness and distensibility of large arteries in healthy adolescents. J Hypertens Suppl 2005; 2: 1707-1715.

26. Rothwell PM. The interrelation between carotid, femoral and coronary artery disease. Eur Heart J Suppl 2001; 22: 11-14.

27. Wu SP, Ringgaard S, Oyre S, Hansen MS, Rasmus S, Pedersen EM. Wall shear rates differ between the normal carotid, femoral, and brachial arteries: an in vivo MRI study. J Magn Reson Imaging 2004; 19: 188-193.

28. Tudor-Locke C, Bassett DR Jr. How many steps/day are enough? Preliminary pedometer indices for public health. Sports Med 2004; 34: 1-8.

29. Machado-Rodrigues AM, Leite N, Coelho-e-Silva MJ, et al. Metabolic risk and television time in adolescent females. Int J Public Health 2015; 60: $157-165$.

30. Christofaro DG, Fernandes RA, Gerage AM, Alves MJ, Polito MD, Oliveira AR. Validation of the Omron HEM 742 blood pressure monitoring device in adolescents. Arq Bras Cardiol 2009; 92: 10-15. 